Diel R, Loytved G, Nienhaus A, et al. New recommendations for contact tracing in tuberculosis. German Central Committee against Tuberculosis [Neue Empfehlungen für die Umgebungsuntersuchung bei Tuberkulose. Deutsches Zentralkomitee zur Bekämpfung der Tuberkulos] Pneumologie 2011; 65: 359-378.

9 Federal Office for Migration and Refugees. Aktuelle Zahlen zu Asyl. Nürnberg, Germany: Federal Office for Migration and Refugees, October 7, 2015. Available from. https://www.bamf.de/SharedDocs/Anlagen/DE/Downloads/Infothek/ Statistik/Asyl/statistik-anlage-teil-4-aktuelle-zahlen-zu-asyl.html Date last accessed: October 12, 2015.

10 Robert Koch Institute. Reports on the Epidemiology of Tuberculosis in Germany [Berichte zur Epidemiologie der Tuberkulose in Deutschland]. Berlin, Germany, Robert Koch Institute. www.rki.de/tuberkulose Date last accessed: September 22, 2015.

11 Zenner D, Zumla A, Gill P, et al. Reversing the tide of the UK tuberculosis epidemic. Lancet 2013; 382: 1311-1312.

12 Marx FM, Fiebig L, Hauer B, et al. Higher rate of tuberculosis in second generation migrants compared to native residents in a metropolitan setting in western Europe. PLoS One 2015; 10: e0119693.

13 De Beer JL, Ködmön C, van der Werf MJ, et al. the ECDC MDR-TB molecular surveillance project participants. Molecular surveillance of multi- and extensively drug-resistant tuberculosis transmission in the European Union from 2003 to 2011. Euro Surveill 2014; 19: pii=20742.

14 Hauer B, Fiebig L, Brodhun B, et al. Tuberculosis surveillance and control in Germany - an application of the Berlin Declaration Monitoring and Evaluation Framework. Eur J Microbiol Immunol 2012; 2: $287-291$.

15 D'Ambrosio L, Dara M, et al. Tuberculosis elimination: theory and practice in Europe. Eur Respir J 2014; 43: 1410-1420.

\title{
Recruitment challenges for clinical trials with novel regimens for drug-resistant tuberculosis
}

\author{
To the Editor:
}

Drug resistance is a growing public health problem. The World Health Organization reported an estimated 480000 new cases of multidrug-resistant tuberculosis (MDR-TB) worldwide in 2013, of which 9\% were estimated to be extensively drug-resistant (XDR)-TB. The prevalence of HIV co-infection among TB patients in the African region is high [1]. In South Africa, 65\% of TB patients tested for HIV are HIV-positive [2].

Treatment for drug-resistant (DR)-TB is long, costly and arduous with consistently poor outcomes and high default rates [2-5]. New treatment options are slowly emerging through clinical trials, while evidence for existing agents is often scarce [6]. Recruitment of suitable subjects for clinical trials has proven challenging at our research site [7,8]. This study aimed to estimate the proportion of potentially eligible subjects among the population with DR-TB in our area and the most frequent reasons of nonparticipation in ongoing clinical trials for DR-TB.

We used the example of two recently completed trials (www.clinicaltrials.gov: NCT00910871 and NCT00449644) to create a set of commonly applicable demographic, social, medical and TB-related criteria for a trial in DR-TB (table 1). Demographic and social criteria aimed to identify cooperative adults likely to comply with rigid visit schedules and long-term follow-up typical of a phase 3 trial. Medical criteria were to exclude subjects at increased risk of adverse events and those with conditions that could interfere with the treatment outcome end-points. HIV-positive subjects not on antiretroviral treatment were allowed (CD4 cut-off at the time was $<250$ cells. $\mathrm{mL}^{-1}$ ). TB-related criteria required documented infection with Mycobacterium tuberculosis with resistance to isoniazid (INH) and rifampin (RIF), but excluded higher-grade resistance if known, and treatment-naive status for the current episode.

At the time of data collection all patients diagnosed with DR-TB in the Cape Town Metropole were referred to a regional centre at Brooklyn Chest Hospital $(\mathrm{BCH})$ in Cape Town to be registered and evaluated for treatment. Resistance testing in the state laboratory for INH and RIF was done with line probe assays and phenotypical testing at that time. GeneXpert and line probe assays for agents other than INH and RIF were not yet available. A Task Applied Science research team (TASK) was situated on the premises of $\mathrm{BCH}$. A single TASK physician (S. Siwendu) retrospectively evaluated the case files of each referral to $\mathrm{BCH}$ for DR-TB for a 3-month period against the criteria in table 1. If a subject seemed not to qualify, the reasons were noted from the records. Individuals were not contacted for additional 


\begin{tabular}{|c|c|c|}
\hline Criterion & Critical value for exclusion & Excluded n (\%) \\
\hline \multicolumn{3}{|l|}{ Demographic } \\
\hline \multirow[t]{2}{*}{ Age years } & $>60$ & $12(2.9)$ \\
\hline & $<18$ & 8 (1.9) \\
\hline Incomplete or outdated records & Not allowed & $27(6.4)$ \\
\hline \multicolumn{3}{|l|}{ Social } \\
\hline Place of living & $>100 \mathrm{~km}$ from site and no transport & $45(10.7)$ \\
\hline Imprisonment or no fixed abode & Not allowed & $28(6.7)$ \\
\hline Member of a gang/criminal organisation & Not allowed & $1(0.2)$ \\
\hline Substance abuse & Not allowed & $19(4.5)$ \\
\hline Alcohol abuse & Not allowed & $35(8.3)$ \\
\hline Previous treatment default & Not allowed & $54(12.8)$ \\
\hline Enrolled in other trial & Not allowed & $11(2.6)$ \\
\hline \multicolumn{3}{|l|}{ Medical } \\
\hline \multicolumn{3}{|l|}{ HIV-positive } \\
\hline CD4 cell count $\mathrm{mL}^{-1}$ & $<250$ & $105(24.9)$ \\
\hline Antiretroviral therapy & Not allowed & $108(25.7)$ \\
\hline Karnofsky score & $<50$ & $44(10.5)$ \\
\hline Insulin-dependent diabetes & Not allowed & $3(0.7)$ \\
\hline Pregnant or breastfeeding & Not allowed & $2(0.5)$ \\
\hline Uncontrolled epilepsy & Not allowed & $1(0.2)$ \\
\hline Malabsorption & Not allowed & $1(0.2)$ \\
\hline QT prolonging co-medication & Not allowed & $27(6.4)$ \\
\hline Other critical co-medication & Not allowed & $14(3.3)$ \\
\hline \multicolumn{3}{|l|}{ Tuberculosis } \\
\hline Treatment initiated & Not allowed & $343(81.5)$ \\
\hline$<2$ weeks & & $139(33.0)$ \\
\hline$<4$ weeks & & $236(56.1)$ \\
\hline Extrapulmonary TB & Not allowed & $4(1.0)$ \\
\hline No resistance documented & Not allowed & $1(0.2)$ \\
\hline Rifampicin monoresistance & Not allowed & $72(17.1)$ \\
\hline Pre-XDR-TB & Not allowed & $26(6.2)$ \\
\hline XDR-TB & Not allowed & $44(10.5)$ \\
\hline MDR-TB treatment failure & Not allowed & $43(10.2)$ \\
\hline
\end{tabular}

TB: tuberculosis; MDR: multidrug-resistant; XDR: extensively drug-resistant.

information. If a subject had no obvious reasons for disqualification, we investigated if the TASK unit had indeed evaluated that subject for participation.

The clinical trials active at that time were approved by the South African Medicines Control Council, the local Ethics Board, and the relevant committees of Cape Town City Health and the Department of Health of the Western Cape of South Africa.

From July 1 to September 30, 2010, a total of 421 patients, aged between 5 and 86 years (median \pm SD $37 \pm 12$ years), 239 (57\%) male, were referred for evaluation. All were culture-positive for $M$. tuberculosis. No record of previous treatment was found in 110 (26\%) primary DR-TB cases (MDR-TB: $n=95$; pre-XDR-TB: $\mathrm{n}=7$; XDR-TB: $\mathrm{n}=8$ ). The main areas for exclusion were HIV-related (CD4 cell counts $<250$ cells $\cdot \mathrm{mL}^{-1}$, antiretroviral treatment), TB-related (resistance to RIF but not INH, resistance to more agents than INH and RIF) and operational, the latter based on the fact that 343 (81.5\%) had been started on treatment before they could be screened and that of 55 referrals (13.1\%) that could have qualified only $12(21.8 \%, 2.9 \%$ of all $)$ were known to and screened by the TASK unit.

This retrospective audit of a large series of consecutive patients referred to a treatment centre for DR-TB showed that $<3 \%$ were screened for participation in a 2 -year clinical trial with a novel agent. This seems low in the face of the great need for novel anti-TB treatments [9]. What can be done to improve this figure?

Many patients will be unequivocally excluded from drug research because of conditions that increase risk or impair compliance with protocol requirements, particularly long-term follow-up. Compromising on safety in the interest of speedy drug evaluation is ethically unacceptable. Yet, there are some areas to contemplate where adaptation in criteria or better preparation could increase participation without increasing risk to participants. 
First, the need to seek regulatory approval for a specific indication such as "MDR-TB" could be reconsidered. "TB resistant to RIF", a growing problem in South Africa and elsewhere [10], would include many more subjects without increased risk and make the results valid to a wider, more practically relevant population. Examples are patients with resistance only to RIF and patients with more extensive resistance for whom a safe and effective background regimen can still be constructed. Second, preparatory interaction studies with commonly used antitretroviral regimens to allow such co-medication would increase both the number of participants and the relevance of the results. Recommendations to use antiretroviral agents early for patients with TB support this [11, 12]. As an alternative to smear-positivity as a proxy for a positive baseline culture (to allow for culture conversion), protocols should consider the late exclusion of participants whose cultures remain negative. Finally, trial protocols with lengthy screening procedures that delay the initiation of treatment are not compatible with the interests of healthcare delivery. It could facilitate collaboration between public healthcare providers and research teams if participants were allowed to be on a background regimen for a limited time that would be modified upon trial participation.

In conclusion, we found that only very few MDR-TB patients were fit for participation in a drug trial for a novel regimen with the criteria applied at the time. Careful consideration of criteria related to HIV infection, antiretroviral treatment, anti-TB treatment and anti-TB drug resistance are critical to make participation more inclusive and to enhance recruitment without compromising safety.

Clinical trials are critical to provide new drugs and regimens not only for high-burden settings, but also for first-world countries striving for TB elimination [13].

@ERSpublications

Enrolment criteria of TB drug trials should be reconsidered to include relevant patient populations in early phases http://ow.ly/U3aoi

Sweetness Siwendu ${ }^{1}$, Melissa Mitchell ${ }^{2}$, Andreas H. Diacon ${ }^{2,3}$ and Florian von Groote-Bidlingmaier ${ }^{2}$

${ }^{1}$ Brooklyn Chest Hospital, Ysterplaat, Cape Town, South Africa. ${ }^{2}$ TASK Applied Science, Bellville, Cape Town, South Africa. ${ }^{3}$ Division of Medical Physiology, MRC Centre for Tuberculosis Research, DST/NRF Centre of Excellence for Biomedical Tuberculosis Research, Faculty of Medicine and Health Sciences, Stellenbosch University, Tygerberg, Cape Town, South Africa.

Correspondence: F. von Groote-Bidlingmaier, TASK Applied Science, Bellville 7530, Cape Town, South Africa.

E-mail: florianv@sun.ac.za

Received: Aug 112015 | Accepted after revision: Oct 202015 | First published online: Dec 032015

Conflict of interest: None declared.

\section{References}

1 World Health Organization. Global tuberculosis report 2014. Geneva, WHO.

2 Cox H, Hughes J, Daniels J, et al. Community-based treatment of drug-resistant tuberculosis in Khayelitsha, South Africa. Int J Tuberc Lung Dis 2014; 18: 441-448.

3 Marais E, Mlambo CK, Lewis JJ, et al. Treatment outcomes of multi-drug resistant tuberculosis patients in Gauteng, South Africa. Infection 2014; 42: 405-413.

4 Migliori GB, Sotgiu G, Gandhi NR, et al. Drug resistance beyond extensively drug-resistant tuberculosis: individual patient data meta-analysis. Eur Respir J 2013; 42: 169-179.

5 Günther G, Gomez GB, Lange C, et al. Availability, price and affordability of anti-tuberculosis drugs in Europe: a TBNET survey. Eur Respir J 2015; 45: 1081-1088.

6 Winters N, Butler-Laporte G, Menzies D. Efficacy and safety of World Health Organization group 5 drugs for multidrug-resistant tuberculosis treatment. Eur Respir J 2015; 46: 1461-1470.

7 Olaru ID, von Groote-Bidlingmaier F, Heyckendorf J, et al. Novel drugs against tuberculosis: a clinician's perspective. Eur Respir J 2015; 45: 1119-1131.

8 Horsburgh CR Jr, Haxaire-Theeuwes M, Lienhardt C, et al. Compassionate use of and expanded access to new drugs for drug-resistant tuberculosis. Int J Tuberc Lung Dis 2013; 17: 146-152.

9 Lessem E, Cox H, Daniels C, et al. Access to new medications for the treatment of drug-resistant tuberculosis: patient, provider and community perspectives. Int J Infect Dis 2015; 32: 56-60.

10 Coovadia YM, Mahomed S, Pillay M, et al. Rifampicin mono-resistance in Mycobacterium tuberculosis in KwaZulu-Natal, South Africa: a significant phenomenon in a high prevalence TB-HIV region. PLoS One $2013 ; 8$.

11 Falzon D, Jaramillo E, Schünemann HJ, et al. WHO guidelines for the programmatic management of drug-resistant tuberculosis: 2011 update. Eur Respir J 2011; 38: 516-528.

12 Amogne W, Aderaye G, Habtewold A, et al. Efficacy and safety of antiretroviral therapy initiated one week after tuberculosis therapy in patients with CD4 counts $<200$ cells/ $\mu \mathrm{L}$ : TB-HAART Study, a randomized clinical trial. PLoS One 2015; 10: e0122587.

13 Lönnroth K, Migliori GB, Abubakar I, et al. Towards tuberculosis elimination: an action framework for low-incidence countries. Eur Respir J 2015; 45: 928-952. 